International Journal of Linguistics, Literature and Translation (IJLLT)

ISSN: 2617-0299 (Online); ISSN: 2708-0099 (Print)

DOI: $10.32996 / \mathrm{ijllt}$

Journal Homepage: www.al-kindipublisher.com/index.php/ijllt

\title{
Indonesian Dishes in the English Target Novel
}

Erlina Zulkifli Mahmud ${ }^{1 *}$, Taufik Ampera ${ }^{2}$, Inu Isnaeni Sidiq ${ }^{3}$

${ }^{1}$ Faculty of Cultural Sciences, Universitas Padjadjaran, Bandung, Indonesia

${ }^{2}$ Faculty of Cultural Sciences, Universitas Padjadjaran, Bandung, Indonesia

${ }^{3}$ Faculty of Cultural Sciences, Universitas Padjadjaran, Bandung, Indonesia

Corresponding Author: Erlina Zulkifli Mahmud E-mail: erlina@unpad.ac.id

\section{ARTICLE INFORMATION}

Received: November 08, 2020

Accepted: December 18, 2020

Volume: 3

Issue: 12

DOI: $10.32996 /$ ijllt.2020.3.12.15

\section{KEYWORDS}

Indonesian dish, non-equivalence

at word level, semantic

components, translation strategy

\section{ABSTRACT}

This article discusses how Indonesian dishes in an Indonesian source novel are translated into the English target novel. The ingredients of the dishes may be universal as they can be found in any other dishes all over the world but the names given to the dishes can be very unique. This uniqueness in Translation Studies may lead to a case of untranslatability as it has no direct equivalence or no one-to-one equivalence known as non-equivalence. For this non-equivalence case Baker proposes 8 translation strategies under the name of translation strategy for nonequivalence at word level used by professional translators. What strategies are used in translating the Indonesian dishes based on Baker's taxonomy and what semantic components are involved in the English equivalences are the objectives of this research. Using a mixed method; descriptive, contrastive, qualitative methods, the phenomena found in the source novel and in the target novel are compared, then documented into a description just the way they are, then analyzed to be identified according to the objectives of the research. The results show that not all translation strategies are used in translating the Indonesian dishes in the novel and the semantic components involved in the English equivalences are mostly ingredients then followed by process, performance, and taste.

\section{Introduction}

Indonesia is a country of various cultures where each culture may have its own specific dish. It can be said that each ethnicity has its own local food leading to a diverse character and uniqueness (Wijaya, 2019). How the dish is prepared in a certain culture and what name is given to may sometimes not be familiar to people from other cultures, even they are Indonesians themselves. Sometimes the same ingredients and the same processes of a certain dish from a certain culture is named differently in other culture, and sometimes the same name may refer to a different kind of dish in other culture and vice versa; a different name of a dish may refer to the same dish in other culture. This condition deals with the fact that the number of Indonesian food, in this case, the dishes, the one that can be the identity of a certain culture is not limited. Surprisingly we can find various kinds of the Indonesian food including the dishes in an Indonesian novel which then is translated into English. This is a chalenging job as a translator is required to have not only the knowledge of the source language but also its culture; a translator has to be able to bring the culture of the source language to the target language (Valencia \& Asmarani, 2016). This work becomes more complicated as not all of the food mentioned in the source language novel accompanied by explanation or description of what the food is about; only some very particular ones.

The amount of the Indonesian food mentioned in the novel cannot be said only several. The fact is that it is ranging from the very popular one to the not very popular one; therefore; it is believed that all Indonesian readers do not have even the knowledge about the food mentioned in the novel.

Food in translation can be categorized as foreign cultural words and it is a part of material culture together with clothes, houses and towns as well as transport (Newmark, 1988) so it needs a certain strategy to translate it. How can we expect the

K C AL-KINDI CENTER
R D
Your gateway to world-doss research
Published by Al-KindiCenter for Research and Development. Copyright (c) the author(s). This is an open access article under CC BY license (https://creativecommons.org/licenses/by/4.0/) 
readers of the target language novel understand these? How can they get the message as expected by the author of the source language text about all those dishes? These depend much on the knowledge of the translator. It is not an easy thing to do especially when the translator is not familiar with the Indonesian culture especially the Indonesian dishes. What can be seen in the English target text is far more than it is expected. Almost all of the Indonesian dishes have their equivalences in the English target novel and it has to be admitted that those English equivalences are communicative although some detail information is not totally right. How the translator provides the information about the Indonesian dishes in the English target novel becomes the main issue discussed in this research article.

The Indonesian food in the same novel including the Indonesian traditional beverage, Indonesian dishes, Indonesian cakes have already been made into a research which is now under reviewed by one of Indonesian journals. What have been used as the data there are those which deal only with couplets translation procedure. This research is performed by the same first author. From the research using Newmark's translation procedure namely couplets, there are still significant number of data left unstudied especially the data about the Indonesian dishes. Based on this, the present research is carried out and based on the condition in the data of the uniqueness of the names of the Indonesian dishes, the study is no longer using Newmark's theory (1988) but Baker's theory (2011).

Referring to the backgrounds discussed in the previous paragraphs, the objectives of this research are to identify what translation strategies are used in translating the Indonesian dishes to identify what translation strategies are used in translating the Indonesian dishes and to describe what semantic components involved in the equivalence. It is expected that the information regarding the Indonesian dishes mentioned in the novel is strengthened by more sufficient information and the readers of both texts; Indonesian source novel and English target novel may acquire the same message.

\section{Literature Review}

As this research focuses on the names of Indonesian dishes mentioned in a novel entitled Pulang by Laela S Chudori which are then translated into English "Home" and since most of the names, any names are unique, the work of the translation lead to a non-equivalence at word level. For this reason, this research uses Baker's strategy of translation for non-equivalence at word level by professional translator (Baker, 2011). Baker categorizes these translation strategies into 8 strategies; (a) translation by a more general word or superordinate which is considered to be the commonest yet this is not the commonest strategy identified in this research; (b) translation by a more neutral/less expressive word; this strategy is not identified in this research; (c) translation by cultural substitution, this deal with the universal characteristics of a dish and it can be found only two in the data of this research; (d) translation using a loan word or loan word plus explanation which can be identified as the commonest strategy in this research especially the loan words plus explanation; (e) translation by paraphrase using a related word; this is the second commonest strategy in this research; (f) translation by paraphrase using unrelated words; this strategy is not found in the data. The information given in the equivalence must deal with related word as when translating the food, the semantic components must consist of elements which are related; (g) translation by omission, this strategy is found in this research though only one; $(\mathrm{h})$ translation by illustration, this strategy though can be very communicative in translating food yet as the data source is a novel and illustration is commonly not provided in a novel so we cannot find any data regarding this strategy.

Along with Baker's translation strategy for non-equivalence at word level by professional translators, this research also involves some previous research articles. This covers three things; the use of Baker's translation strategy in previous research articles in journals; the previous researches dealing with the translation of food; the previous researches dealing with the same data source, the novel Pulang.

Baker's translation strategy for non-equivalence at word level by professional translators have been used to study other field like the translation of four dialects in Africa in informative text (Angatia, 2018), the dialects involve the non-equivalence at word level. Any field that relates to the case of translating the non-equivalence at word level can be managed by the use of Baker's translation strategy. It is one of the reasons that it can also be found in the previous research regarding the translation of the Islamic and Arabic cultural terms into English (Alhumaid, 2015). The problems dealing with the Islamic and Arabic cultural terms which are categorized as untranslatability is due to the fact that there is no direct equivalence or oneto-one equivalence for certain Islamic and Arabic cultural words. As the effort to overcome these the translator applies Baker's translation strategy. For a certain reason that the unique characteristics commonly found in cultural words where we cannot find direct equivalence for them, this Baker's translation strategy is also found in the previous research dealing with the translation of Indonesian novel into English, Ahmad Tohari's dancer (Nitisari, 2016). 
The next previous researches used as references for this present research deal with the translation of food as in menus, in advertising text as well as in marketing. There are various ways translators use as their translation tool; technique of translation, procedures of translation, and other strategies of translation. The most current research which is taken as one of the references is the article in a journal regarding the translation strategies of food which are related to culture specific items from English into Indonesian specifically in Indonesian subtitle broadcasted by Netflix series entitled The Final Table (Farkhan et al., 2020). This research covers the discourse analysis on food terminologies in Indonesian subtitle in the UK and USA episodes and the translation of the food is studied by applying Pederson's translation strategy. While the researches dealing with the translation of food in menus first found in the translation from Polish into English which is considered to be difficult to comprehend as a cultural outsider (Chłopicki, 2018). This leads to the research question whether this because of the case of untranslatability as cultural words or it is because of the lack of cultural knowledge of the translator. The second research is a master degree thesis which deals with the translation of menus from English into Arabic (Saleh, 2011). In this thesis, the problems found in the translation are identified and are related to several theories of Translation Studies taken from scholars such as, Venuti, Newmark, Hatim. The strategies to overcome the problems are mainly adaptation which is preceded by transliteration and borrowing. The third research deals with the strategies in translating restaurant menu using domestication and foreignization translation strategies (Ghafarian et al., 2016). Domestication is needed to make the target text understandable and reader friendly while foreignization is needed to adjust the reader to the source culture. Using the same main theories, domestication and foreignization, the next research used as one of the references is about the analysis of the role of food and its translation relating to the process of globalization in the dubbed versions of animated films the Shrek saga (González-Vera, 2015).

The translation of food in advertising text can be referred to the thesis of master degree at University of South Africa discussing the translation of fast-food in advertising text from English into Arabic (Al Agha, 2007).

All food advertisements are considered to be culturally bound to their originals, the source text. What translation strategies used in the translation work are identified. A bit different from other researches, the next previous research talks about a bigger frame of translation work, tourist communication, which involves also the translation of food. As other translations of food, it also discusses the major problem dealing with the translation work due to the cultural content in them (Merkaj, 2013). It reveals that the challenge dealing with the specialized discourse like tourist discourse; that is when a translator needs to introduce a reality including a type of food to a person who may have never heard of it. Unlike any other references discussed before, this one talks about the translation of food involving interdisciplinary approach based on the fact that the relationship between food, culture and translation is still under-researched (Chiaro \& Rossato, 2015).

Dealing with the detail semantic components of the Indonesian dishes, this present research uses some references taken from some Indonesian Food links in the internet: www.wikipedia.org as it gives detail information than any other internet links and https://cookpad.com as it provides various Indonesian food from the very popular one into less popular one. Not only the internet links this research also uses a book under the tile of The Food of Indonesia Delicious Recipes from Bali, Java and the Spice Islands; this book covers the information about food in Indonesia, Indonesian kitchen, cooking methods, authentic Indonesian ingredients (Holzon \& Arsana, 2007).

\section{Methodology}

This research uses qualitative, descriptive and contrastive method. Qualitative research method is used as this research involves the activities of collecting data as well as analyzing data which are not numerical (Bhandari, 2020). The function of this research method is to understand the concepts, opinions, or experiences in this case is the concepts of Indonesian dishes mentioned in the novel. The data which are taken only the data which are assumed to have cultural content in its names. While the descriptive research method is used as it is aimed to describe the phenomena accurately and systematically (McCombes, 2020). What are discussed in this research are expressed in a form of description and what phenomena dealing with the Indonesian dishes are described as the ways they are, objectively, and they are discussed in a systematic way based on each translation strategy taken from Baker.

The next research method is contrastive analysis method as it deals with two texts (the source text and the target text). It involves an activity of comparing several aspects available in two languages in order to get both the similarities and differences (Sukirmiyadi, 2018). There are two steps taken regarding this comparing activity; (1) to compare what is written in the source text with its equivalence in the target text; and (2) to compare what is written in the target text with the references taken from the book and Indonesian food links in internet. From the two steps of comparing, the semantic components revealed in the equivalences can be identified. Through this research, additional information dealing with each 
Indonesian dish is described. This additional information is aimed at strengthening the information given in the equivalences found in the English target novel.

\section{Results and Discussion}

Chapter 4 is divided into several parts based on the translation strategies given by Baker found in the data. Each strategy is presented in a table consisting of the equivalences for the Indonesian dishes. Out of 8 strategies included in the taxonomy, only 5 strategies found in the data in this research.

\section{A. Translation by a More General Word}

For other cultural words, this first translation strategy; translation by a more general word may be the commonest strategy but not with the translation of food, not in this research. There are only 2 data regarding this first translation strategy; tempe kering and sup brenebon as it can be seen in the table 1.

Table 1: The Equivalences of Indonesian Dishes in More General Words

\begin{tabular}{|l|l|l|}
\hline No. & Indonesian Source Language Text & English Target Language Text \\
\hline 1 & Tempe kering & crispy tempeh \\
\hline 2 & Sup brenebon & kidney-bean soup \\
\hline
\end{tabular}

The dish tempe kering in data (1) and (14) is the same; it reveals 2 times because the name of the dish is translated into 2 different strategies. It has to be noted that when the word tempe is put after kering "kering tempe" like in data (21), the name of the dish refers to the different kind of dish. Here in data (1) tempe kering is translated into crispy tempeh using translation strategy by a more general word as the word kering 'dry or dried' as a part of the name of the dish is simply translated literally into crispy as the result of making food dry; how it is cooked or processed is not mentioned. The word tempe itself has already got the one-to-one equivalent in English, tempeh; it is made from fermented soybeans and originated from Java. Seeing from the equivalence given, it can be identified that the semantic components contained in crispy tempeh are ingredients; tempeh, and performance; crispy. The dish under the name of tempe kering is popular in all Indonesian cultures. Everybody knows this dish and everybody eats this. Unfortunately, the readers of the target language text may not have the same knowledge as the readers of the source language especially on how the tempeh is processed or cooked, whether it is fried or baked.

In data (2), the name of the Indonesian dish sup brenebon is translated into kidney bean soup, using the same strategy; by a more general word. What makes this more general due to some reasons; that soup in Indonesian dish is not limited into one kind of soup, it is various. When it is translated into kidney-bean soup, the readers of the target language text will have no knowledge that the soup has a specific name, brenebon, and this name is given to a certain soup from a certain ethnic or culture in Indonesia, Menado (North Sulawesi) cuisine. Based on the equivalence given, it can be identified that the semantic components involved are of 2: the performance of the food: soup; and the main ingredient: kidney-bean. What other ingredients are used in the dish and other information like the origin of the food are not revealed.

\section{B. Translation by Cultural Substitution}

There are 2 data involving this translation strategy, translation by cultural substitution: telur dadar and urab. The name of the Indonesian dish "urab" in data (4) of table 2 can also be found in data (7) and (19), as well as "sayur urab" in data (8); they all refer to the same dish; boiled or blanched vegetables mixed with spicy grated coconut. However, the strategies the translator uses to reveal the equivalences are different. The following table: table 2 consists of the Indonesian dishes which are translated using cultural substitution.

Table 2: The Equivalences of Indonesian Dishes in Cultural Substitution

\begin{tabular}{|l|l|l|}
\hline No. & Indonesian Source Language Text & English Target Language Text \\
\hline 3 & Telur Dadar & wafer-thin omelette \\
\hline 4 & Urab & wilted vegetables \\
\hline
\end{tabular}


It is not surprising to find out that the specific Indonesian dish may have cultural substitution as found in data (3) and in data (4). This is due to the fact that food as any other cultural words may contain both universal and specific characteristics. The name of the food or dish may be different but the reference of the dish can be the same. Telur dadar in data (3) which refers to the frying egg which is first mixed then fried thinly is translated into wafer-thin omelette. Both wafer and omelette are specific food which can be found in the target language culture; both of them are popular so when the readers of the target language read this equivalence, they will have the same knowledge as the readers of the source language of what the dish is discussed. The semantic component found in the equivalence, wafer-thin omelette is the performance: thin like wafer. There is no explicit information regarding the ingredients, egg as it is not necessary. The readers of the target language text have already known that omelette is made from egg, and it is mixed before frying.

In data (4) "urab" is translated into "wilted vegetables" using translation by cultural substitution containing the semantic components performance; wilted, and ingredient; vegetables. This is not the same at all. The process of making or cooking in the dish wilted vegetables or wilted greens is stir fried while urab is boiled or blanched. The only similarity is only in the main ingredients: vegetables.

\section{Translation Using a Loan Word or Loan Word Plus Explanation}

There are 10 data of the Indonesian dishes under this translation strategy and there is only one as a loan word without explanation: gado-gado. There is one dish namely ikan pindang serani in data (10) having several equivalences with different details but each equivalence is always preceded by the loan word. All data involving this strategy are given in table 3 as follow.

Table 3: The Equivalences of Indonesian Dishes in A Loan Word or Loan Words Plus Explanation

\begin{tabular}{|c|c|c|}
\hline No. & Indonesian Source Language Text & English Target Language Text \\
\hline 5 & Gado-gado & Gado-gado \\
\hline 6 & Gulai Pakis & $\begin{array}{l}\text { Gulai pakis, fiddlestick ferns simmered in coconut } \\
\text { sauce, }\end{array}$ \\
\hline 7 & Urab & urap, spiced vegetables with grated coconut \\
\hline 8 & Sayur Urab & $\begin{array}{l}\text { Sayur urap, mixed steamed vegetables with } \\
\text { spiced coconut; }\end{array}$ \\
\hline 9 & Soto ayam & soto ayam, spicy yellow chicken soup \\
\hline \multirow[t]{3}{*}{10} & Ikan pindang serani & $\begin{array}{l}\text { Ikan pindang serani Originally an Indo-Portuguese } \\
\text { dish; spicy and sour milkfish soup; the fish which } \\
\text { had been simmered slowly in turmeric sauce }\end{array}$ \\
\hline & & $\begin{array}{l}\text { Ikan pindang serani Javanese spicy and sour } \\
\text { milkfish soup }\end{array}$ \\
\hline & & $\begin{array}{l}\text { Ikan pindang serani, the spicy and sour milkfish } \\
\text { soup }\end{array}$ \\
\hline 11 & Ayam goreng keremes & $\begin{array}{l}\text { Ayam goreng keremes; coconut battered fried- } \\
\text { chicken }\end{array}$ \\
\hline 12 & Gulai Anam & $\begin{array}{l}\text { Lampung-style curried chicken dish called gulai } \\
\text { anam, }\end{array}$ \\
\hline 13 & Sambal goreng udang & $\begin{array}{l}\text { Sambal goreng udang-which are shrimp cooked } \\
\text { in a chili sauce," }\end{array}$ \\
\hline 14 & Empal & empal, seasoned slices of tenderized fried beef \\
\hline
\end{tabular}

In data (5) the Indonesian dish "gado-gado" is translated using a loan word only, no explanation following the loan word. The readers of the target language text may totally have no idea about this name "gado-gado" that it is actually an Indonesian salad of boiled or blanced vegetables in a spicy peanut sauce and usually it is served with slices of boiled potato and egg together with fried tofu and tempeh. 
Going to data (6) the name of the Indonesian dish "gulai pakis"is translated by using a loan word plus explanation: gulai pakis, fiddlestick ferns simmered in coconut sauce. It contains the semantic components: ingredients: fiddlestick ferns, coconut; and process: simmered; as well as performance: gulai in coconut sauce. Gulai pakis or gulai paku is a Minangese dish (West Sumatra) and it is spicy. The readers of the target language may have no knowledge about the taste that it is spicy or hot as mostly Minangese dishes use chili in its cuisine.

Data (7) regarding the Indonesian dish namely "urab" and data (8) "sayur urab" refer to the same dish which is a mix of blanced vegetables with spices and grated coconut and it is originally from Java island. This dish is popular among Indonesian people of any culture. Under the strategy of translation using loan words plus explanation, urab is translated into urab, spice vegetables with grated coconut while sayur urab is translated into sayur urab, mixed steamed vegetables with spiced coconut. The equivalence of the Indonesian dish urab involves semantic components: process: spice, grated; ingredients: vegetables, coconut. While the equivalence of sayur urab involves semantic components: process: mixed, steamed, spiced and ingredients: vegetables and coconut. From the semantic components, the readers of the target language will have no idea that the taste of the dish is commonly spicy or hot as chili is always used.

In data (9) we can find one of the very popular Indonesian dishes called soto ayam. Soto is a traditional soup commonly found in Indonesian cuisine while soto ayam can be explained as Indonesian traditional soup with turmeric added as one of its ingredients to the chicken broth. The name soto ayam is translated under this strategy so the name soto ayam is kept in the target language as a loan word and it is followed by the explanation: soto ayam, spicy yellow chicken soup. The semantic components involved are ingredients: chicken, taste: spicy, and performance: yellow, soup. By this equivalence, the readers of the target language will get the knowledge what this dish is about though no detail ingredients revealed. What the readers may not have any idea is that the taste spicy is not because of chili but because of the mixt of spices like; turmeric and ginger.

The next Indonesian dish is called ikan pindang serani as written in data (10). It has 3 different detailed equivalences. The first time when it reveals in the text, it is translated in an elaborative way: ikan pindang serani, originally an Indo-Portuguese dish; spicy and sour milkfish soup; the fish which had been simmered slowly in turmeric sauce which covers semantic components: ingredients: milkfish, turmeric; taste: spicy, sour; process: simmered; manner: slowly; performance: soup, sauce; history: originally an Indo-Portuguese dish. While in the second equivalence in the next part of the text, it is translated still using the loan word plus explanation into ikan pindang serani, Javanese spicy and sour milkfish soup. It can be identified that the equivalence consists of the following semantic components: ingredients: milkfish, taste: spicy, sour; performance: soup; and origin: Java. The readers of the target language will have the same knowledge about the dish only minus the history. As in the third equivalence, the name of the Indonesian dish ikan pindang serani is translated in simpler explanation but still keeps the loan word, ikan pindang serani into Ikan pindang serani, the spicy and sour milkfish soup. The third equivalence involves the semantic components: ingredients: milkfish; taste: spicy, sour; performance: soup. By this equivalence, the readers of the target language will have the knowledge about what the dish is including the taste.

The loan word plus explanation can also be found in the translation of data (11) "ayam goreng keremes". This Indonesian dish is translated into Ayam goreng keremes; coconut battered fried-chicken involving semantic components: ingredients: chicken, coconut; process: battered, fried; performance: ayam goreng keremes. Actually, there are various kinds of ayam goreng 'fried chicken' in Indonesian dish and ayam goreng keremes is one of them. This dish is said to be originated from Javanese cuisine. The term "kremes" refers to the crunchy condiment as the toping. The crunchy condiment is not made from coconut as in the equivalence. The fried chicken with crunchy condiment of coconut is called ayam serundeng. The readers of the target language will have the knowledge of the name of the Indonesian dish ayam goreng kremes and they will know that it is fried chicken, other detail is shifted.

Data (12) gulai anam refers to a specific dish commonly served in led ceremony in Lahat, South Sumatra as well as in Palembang, the capital city of South Sumatera. It is chicken curry with vegetable. In data (12) it is translated using the loan word plus explanation: gulai anam, Lampung-style curried chicken dish involving semantic components: ingredients: chicken; process: curried; performance: Lampung-style. Lampung in the equivalence is a place in Sumatra island, Lampung province, it is not in South Sumatra province though most of the dishes there are almost the same as the dishes of Palembang cuisine.

The Indonesian dish in data (13) is called sambal goreng udang which is made of shrimp cooked in rich, hot and spicy chili pepper sauce. It is originated from Minangkabau cuisine, West Sumatra. The chili pepper sauce in this dish is also known as balado. In the target text, the name of the dish is translated using loan word plus explanation sambal goreng udang-which are shrimp cooked in a chili sauce; involving the semantic components: ingredients: shrimp, chili; process: cooked; performance: in a chili sauce. The information given in the equivalence will give the readers of the target text almost the same knowledge 
as the readers of the source language; what is missing here that the process of cooking in this sambal goreng udang; that is by frying.

The last dish mentioned in this table 3 is known as empal (14). It is sometimes known as empal gepuk or just empal or just gepuk. It refers to the sweet and spicy fried beef dish. It is originated from Sundanese cuisine, West Java where in Sundanese cuisine it is called gepuk and it is not spicy as in Javanese cuisine. The dish empal is translated using the translation strategy; translation by using a loan word plus explanation into empal, seasoned slices of tenderized fried beef. By the description given in the equivalence it can be identified its semantic components: ingredients: beef, season; process: seasoned, tenderized, fried; performance slices. The readers of the target text will have almost similar knowledge as the readers of the source language text. What missing here is the information of its taste; sweet.

\section{Translation by Paraphrase Using a Related Word}

This fourth translation strategy becomes the second commonly used in translating the Indonesian dishes written in a novel. There are 7 data can be put in this table 4 regarding this strategy.

Table 4: The Equivalences of Indonesian Dishes by Paraphrase Using a Related Word.

\begin{tabular}{|l|l|l|}
\hline No. & Indonesian Source Language Text & English Target Language Text \\
\hline 15 & Tempe kering & $\begin{array}{l}\text { little sticks of tempeh soaked in brine and then } \\
\text { fried until crispy }\end{array}$ \\
\hline 16 & Ayam balado & braised chicken in a chili and shrimp-paste sauce \\
\hline 17 & Tahu isi & tofu dish that's been stuffed \\
\hline 18 & Sambal bajak teri & $\begin{array}{l}\text { fried hot pepper sauce with dried and salted } \\
\text { white fish }\end{array}$ \\
\hline 19 & Urab & steamed vegetables with grated coconut. \\
\hline 20 & Kering tempe & tempeh sticks with peanuts and chilli \\
\hline 21 & Balado teri kacang & fried anchovies and peanuts in chili sauce \\
\hline
\end{tabular}

The Indonesian dish using the terms tempe and kering has already been discussed in table 1 data (1) with the same construction as in data (15). It is translated into little sticks of tempeh soaked in brine and then fried until crispy with the related words fried, tempeh and crispy involving the semantic components; ingredients: tempeh, brine; process: soaked, fried; performance: little sticks, crispy. This equivalence can fulfil the information needed by the readers of the target text in understanding what tempe kering is. While in data (20) the two terms, tempe and kering are used in different construction "kering tempe" pointing to the different kind of dish. It is also made from tempeh but the cooking process, the ingredients, as well as the performance are not the same. Kering tempe is very common dish in Indonesia usually served with yellow rice and it is cut into small cubes, fried with sweet and spicy glace. In this data (20) the dish kering tempe is translated by paraphrase using a related word into tempeh sticks with peanuts and chilli. The related words in the paraphrase are tempeh, peanuts, and chili as the main ingredients. The readers of the target text will be aware that they deal with the different dish for in the data (20) it is seen from the equivalence that the dish is made from not only tempeh but also peanuts and it is spicy as it uses chili.

The next dish in table 4 of data (16) is called ayam balado and as other data in this table, they are all translated by paraphrase using a related word. Ayam balado is a spicy Indonesian dish made of chicken and the term balado is Minangese term for a fragrant chili called sambal made simply from a blend of shallots, chili, garlic, and lime leaves and this sambal is then stir fried with vegetable oil. The chicken is also fried. In this data, it is translated into braised chicken in a chili and shrimp-paste sauce. The paraphrase uses related words: chicken and chili yet there is a shift in Minangese or Padang cuisine, balado commonly is used for fried dish and shrimp-paste sauce is not used. 
Using the same strategy, translation by paraphrase using a related word, the name of Indonesian dish tahu isi (17) is translated into tofu dish that's been stuffed. The related words found in the equivalence are tofu and stuffed, and the semantic components in it are ingredients: tofu; process: stuffed. Tahu isi in Indonesian cuisine is very popular as snack, people can buy it on the street stall everywhere. The tofu is deep fried and stuffed with vegetables. The readers of the target language may have enough knowledge with this equivalence. What they do not know that what stuffed with is vegetables.

The next Indonesian dish in this table 4 is called sambal bajak teri which is translated into a paraphrase "fried hot pepper sauce with dried and salted white fish". The related words used are fried hot pepper sauce, salted fish and the semantic components involved are ingredients: hot pepper, white fish; process: fried, dried, salted; taste: hot. Sambal bajak in Indonesian dish is considered to be not too hot; mild and sambal bajak teri is dried and salted anchovy which is fried then mixed with chili sauce which is not too hot or mild. Using the equivalence given in the novel, the readers of the target text will have no idea that the fish which is discussed is actually dried, salted anchovy not white fish.

As it can be seen in the previous tables; table 2 and table 3, the name of the Indonesian dish "urab" has been discussed under the two translation strategies; translation using cultural substitution and translation using a loan word plus explanation. Urab as written in data (19) is translated not using loan word anymore but by paraphrase using a related word into steamed vegetables with grated coconut. The related words here are vegetables and grated coconut. Based on the equivalence it can be identified that the semantic components involved are ingredients: vegetables, coconut; process: steamed, grated. It is assumed that the translator uses this strategy because the name of the dish "urab" has been discussed several times previously in the text. The lengthy explanation may not be needed anymore. However, there is a shift occurred in the equivalence that the cooking process is not steamed but blanched or boiled.

The last dish in this table is balado teri kacang (21) which refers to the dish of dried salted anchovy and fried peanuts in fried chili sauce. This is one of the popular dishes known in all over Indonesia. When it is translated into the target text using the strategy of translation by paraphrase using a related word, the equivalence given is the fried anchovies and peanuts in chili sauce. The related words are anchovies, peanuts, chili sauce. The semantic components involved are ingredients: anchovy, peanut, chili; process: fried; performance: in chili sauce. The readers of the target text will have sufficient information regarding this dish. What is missing is the information that the anchovy in the dish is the dried and salted one.

\section{E. Translation by Omission}

In translating the Indonesian dishes written in an Indonesian novel, there is one dish which is not translated as others. The dish is simply omitted in the target language text. It is assumed that it is because the name of the dish is attached directly to the name of a street stall: warung bakmi godog.

Table 5: The Equivalences of Indonesian Dishes by Omission

\begin{tabular}{|l|l|l|}
\hline No. & Indonesian Source Language Text & English Target Language Text \\
\hline 25 & Bakmi godog & \\
\hline
\end{tabular}

Bakmi godog is a very popular dish mostly sold in the street stall. It is made of traditional noodle with vegetables, shredded chicken, and egg and it is boiled commonly using firewood or charcoal. It is originated from Javanese cuisine. The translator omits this dish from the text together with the word "warung" (stall) which is attached to the name of the Indonesian dish.

\section{Conclusion}

From the discussion in this research article, it can be concluded that not all strategies in Baker's taxonomy of translating the non-equivalence at word level can be implemented. There are only 5 strategies: (1) translation by a more general word; (2) translation by cultural substitution; (3) translation using a loan word or loan word plus explanation; (4) translation by paraphrase using related word; (5) translation by omission. The three others: translation by a more neutral/less expressive word; translation by paraphrase using unrelated word; translation by illustration are not found in the data. Translation by a more neutral/less expressive word cannot be used in translating the names of dishes which have unique names as no expressive word used in the names. Translation by paraphrase using unrelated word cannot be used either as what needs to be revealed in the equivalence for the names of dishes is related word, either related to the ingredients, process, performance, or taste. While translation by illustration which can be more communicative in translating dishes cannot be used as the text where the names of the dishes is not a book but a novel. Novel usually does not use illustration in describing a story unlike comics. 
The semantic components identified in the equivalences are ingredients, process, performance, taste, and origin. Ingredients are the semantic components mentioned in all dishes except one in table 2 data (3) "wafer thin omelette". It is assumed that all readers of the English target novel have the knowledge that the main ingredients of omelette is egg. The semantic components, process, performance, taste, and origin are not always mentioned. Baker's strategies of translation are not the only approaches that can be used to study the translation of the Indonesian dishes. Newmark's procedures of translation such as functional equivalent, descriptive equivalent, cultural equivalent, borrowing can be other options.

\section{References}

[1] Al Agha, A. B. (2007). THE TRANSLATION OF FAST-FOOD ADVERTISING TEXTS FROM ENGLISH TO ARABIC by BASEM ABBAS AL AGHA. University of South Africa.

[2] Alhumaid, A. (2015). The Untranslatability of Islamic and Arabic Cultural Terms. International Journal of Language and Linguistics, 2(3), 99-102. www.ijllnet.com

[3] Angatia, B. M. (2018). Baker's Strategies in Translation : A Lexico-Semantic Analysis of Four Luhya Dialects ; Lukabras , Lwisukha , Luwanga and Lukhayo in Informative Text. AJESS, 3(September), 71-84.

[4] Baker, M. (2011). In Other Words: A coursebook on translation, second edition. In In Other Words: A coursebook on translation (3rd ed.). Routledge Taylor and Francis Group.

[5] Bhandari, P. (2020). What is Qualitative Research? | Methods \& Examples. In Scribbr.Com. https://www.scribbr.com/methodology/qualitative-research/

[6] Chiaro, D., \& Rossato, L. (2015). Introduction: Food and translation, translation and food. Trans/ator, 21(3), $237-243$. https://doi.org/10.1080/13556509.2015.1110934

[7] Chłopicki, W. (2018). Translation of menus: Labour of sisyphos, squaring the circle or marrying water and fire? Folklore (Estonia), 71, 155-178. https://doi.org/10.7592/FEJF2018.71.chlopicki

[8] Farkhan, M., Naimah, U. L., \& Suriadi, Agus, M. (2020). Translation Strategies of Food-Related Culture Specific Items in Indonesian Subtitle of Netflix Series The Final Table. Insaniyat, 4(2).

[9] Ghafarian, M., Kafipour, R., \& Soori, A. (2016). Domestication and foreignisation strategies in restaurant menu translation. Pertanika Journal of Social Sciences and Humanities, 24(4), 1417-1429.

[10] González-Vera, P. (2015). Food for thought: The translation of culinary references in animation. Ikala, 20(2), $247-264$. https://doi.org/10.17533/udea.ikala.v20n2a07

[11] Holzon, H. von, \& Arsana, L. (2007). The Food of Indonesia: Delicious Recipes from Bali, Java and the Spice Island. Tuttle Publishing.

[12] McCombes, S. (2020). Descriptive Research Design | Definition, Methods and Examples. In Scribbr (pp. 2-3). https://www.scribbr.com/methodology/descriptive-research/

[13] Merkaj, L. (2013). Tourist Communication: a Specialized Discourse With Difficulties in Translation. European Scientific Journal, 2(December), 1857-7881.

[14] Newmark. (1988). A Textbook of Translation (1st ed.). Prentice Hall International (UK) Ltd.

[15] Nitisari, D. (2016). The Translation Strategies of Cultural Words in Ahmad Tohari , s Dancer. UG Journal, 10(03).

[16] Saleh, K. A. H. (2011). Translating Restaurants 'Menus from English into Arabic : Problems and Strategies. An-Najah National University.

[17] Sukirmiyadi. (2018). The Role of Contrastive Analysis in Translation Study. International Journal on Studies in English Language and Literature, 6(9), 30-34. https://doi.org/10.20431/2347-3134.0609004

[18] Valencia, W \& Asmarani, R. (2016). The Translation Procedures of Cultural Expressions Applied in " A Game of Thrones ." LITE Journal, $12(2), 20$.

[19] Wijaya, S. (2019). Indonesian food culture mapping: A starter contribution to promote Indonesian culinary tourism. Journal of Ethnic Foods, 6(1), 1-10. https://doi.org/10.1186/s42779-019-0009-3 